\title{
The effect of viewing position on the perceived layout of space
}

\author{
RICHARD C. TOYE \\ University of Illinois at Chicago, Chicago, Illinois
}

\begin{abstract}
Eight observers judged the location of 13 objects in an open field by drawing a map of the scene, estimating absolute distances between objects, and rank ordering subsets of distances. Half the observers made judgments twice from the same position while the rest moved $90^{\circ}$ around the scene before making the second set of judgments. Scaled judgments showed a strong visible similarity to the actual spatial layout of the scene. Observer judgments changed significantly as a function of observer position. A portion of this effect was due to a perceptual shortening of radial distances. These results were taken to support the classical psychophysical model of space perception rather than a strong ecological model and to emphasize the importance of the subjective element of visual space perception.
\end{abstract}

Visual space perception has been described in two major theoretical frameworks, the classical Helmholtzian psychophysics and Gibsonian ecological psychophysics (Haber, 1980). In spite of a lack of consistent evidence supporting either model, both are widely accepted. The present study attempted to provide a test between the two.

The classical approach to space perception reduces visual space to a Euclidean coordinate system (Haber, 1984). Space is defined in terms of its height, breadth, and depth. The physical properties of the retina are used to argue that height and breadth are retinotopic translations of optical stimulation, whereas depth is captured through more complex mechanisms (Held, Leibowitz, \& Teuber, 1978; Hochberg, 1978). The psychophysical functions of estimation of breadth and depth differ (Marks, 1974), supporting this contention. Depth information is provided by hard-wired mechanisms such as stereopsis and convergence (Gogel \& Tietz, 1979; Gulick \& Lawson, 1976) and local cues such as motion parallax, overlap, and perspective (Farber \& McConkie, 1979; E. J. Gibson, J. J. Gibson, Smith, \& Flock, 1959; Goodson, Snider, \& Swearingen, 1980). The unconscious inference of depth through these cues is the basis of the classical explanation of space perception.

Classical psychophysics defines space perception in a static fashion. The breadth of a scene, the frontoparallel plane, and the depth, the radial axis parallel to the line of sight and perpendicular to the breadth, are redefined with each motion of the observer's head. Spatial calculations are, theoretically, integrated across successive glimpses of a visual array to derive a description of spatial layout.

This research was supported in part by the Office of Social Science Research at the University of Illinois at Chicago. I gratefully acknowledge the contributions of Ralph and Lyn Haber in organizing the report of this research.

Requests for reprints should be sent to the author at New Hampshire Hospital, Brown Building, 105 Pleasant Street, Concord, NH 03301.
The static nature of this approach has been criticized (Haber, 1984). There is some evidence that visual integration of static glimpses does not occur (Irwin, Yantis, \& Jonides, 1983). Empirical support for the cues described in the model is weak. Approximately half of the published studies of the major inferential cue of motion parallax, for example, report the cue to be ineffective in inducing depth discrimination (Gogel \& Tietz, 1979). When depth effects are found, observers tend to be extremely variable (Ferris, 1972; E. J. Gibson et al., 1959; Gilinsky, 1951; Graham, Baker, Hecht, \& Lloyd, 1948; Hell \& Freeman, 1977; Wheeler \& Rock, 1982), or the cue is found to provide only partial information about spatial extent (Hagen \& Teghtsoonian, 1981). The explanation for these results is typically that the observer attends to and integrates information from multiple cues that are differentially effective in different settings (Haber, 1980).

An alternative psychophysical description of spatial perception has been suggested by J. J. Gibson (1979) and has been further developed by others (Michaels \& Carello, 1981). In this environmental psychophysics, the observer is afforded direct perceptual interaction with the scene of which he is a part. Perceived spatial extent depends on information provided through complex mechanisms which may have no direct reference to an internal coordinate system (see, e.g., Runeson, 1977). These internal mechanisms are presumed to be universal and invariant: They exist and operate identically in all visual environments with which the observer is familiar. The observer is characterized as an essential component of the perceptual process.

It may be argued, however, that the Gibsonian model has failed to make a case for its position (Epstein \& Park, 1964). Ecological investigators have focused their efforts on describing a few "intelligent mechanisms." These mechanisms are typically tested in a laboratory setting using extrapolated stimuli that represent natural variables schematically (J. J. Gibson \& Carel, 1952; Runeson, 
1977). As a result of this isolation of cues, Gibsonian mechanisms such as motion perspective increasingly resemble the classical cues.

There is a need to examine visual space perception in a manner that provides an opportunity for both classical and environmental mechanisms to operate and allows the predictive value of the two models to be compared. Such a stimulus situation has been used in the study of visual memory (Kosslyn, Pick, \& Fariello, 1974), with observers being provided with a natural visual array and later being asked to recall the distances between objects in the array. Multidimensional scaling (MDS) was used to construct a model of the observers' cognitive maps of the array, and the effect of environmental variables on visual memory was inferred through distortions in the scaled maps. Although MDS typically is used to capture relations among such constructs as affect or memory, it may be useful in measuring direct visual perception as well (Marks, 1974). A recent application of multidimensional methodology in a natural visual array compared four geometries used to describe spatial perception (Wagner, 1985).

The nature of the visual information described by the two major theories of spatial perception suggests a way of discriminating between the two using such a natural visual array and MDS. Data from classical investigations depict space perception as a system in which depth and the dimensions of height and breadth are calculated differently. As a viewer at one point on the periphery of a scene moves $90^{\circ}$ around the scene, the planes defined as depth and breadth are interchanged, and should be reported as being perceived differently, since, according to traditional findings, the involved psychophysical mechanisms differ. The ecological model, on the other hand, relies on invariant affordances common to all scenes (J. J. Gibson, 1979). These invariants should provide adequate ecological information from all perspectives with no predictable alteration with change in viewing position.

\section{METHOD}

\section{Subjects}

Eight male graduate students with no previous psychophysical experience participated as observers. They were screened for binocular visual normality. The observers were assigned randomly to a control (no shift) group or an experimental (position shift) group.

\section{Stimuli}

Observers judged the distances between 13 white metal stakes which were placed in a flat grassy field in an approximately $21-\mathrm{m}(70-$ $\mathrm{ft}$-diam circular stimulus area. The field was approximately four times the size of the stimulus area and was bounded by tall build-

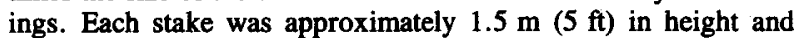
$3.8 \mathrm{~cm}$ (1.5 in.) in diameter. Each was topped with a $23-\mathrm{cm}$ (9-in.) triangular sign bearing a unique letter from $\mathbf{A}$ to $\mathbf{M}$. Stakes were placed in a uniform random fashion, with the exception of two stakes which were placed on two adjacent edges of the stimulus space, perpendicular with respect to each other and the center of the array. Distances between the stakes ranged from $61 \mathrm{~cm}(2 \mathrm{ft})$ to $21 \mathrm{~m}$ $(70 \mathrm{ft})$ with a mean distance of $11.4 \mathrm{~m}(37.5 \mathrm{ft})$ and a standard deviation of $4.8 \mathrm{~m}(15.7 \mathrm{ft})$. The range of interobject distances was approximately normally distributed. When the observer was at stake

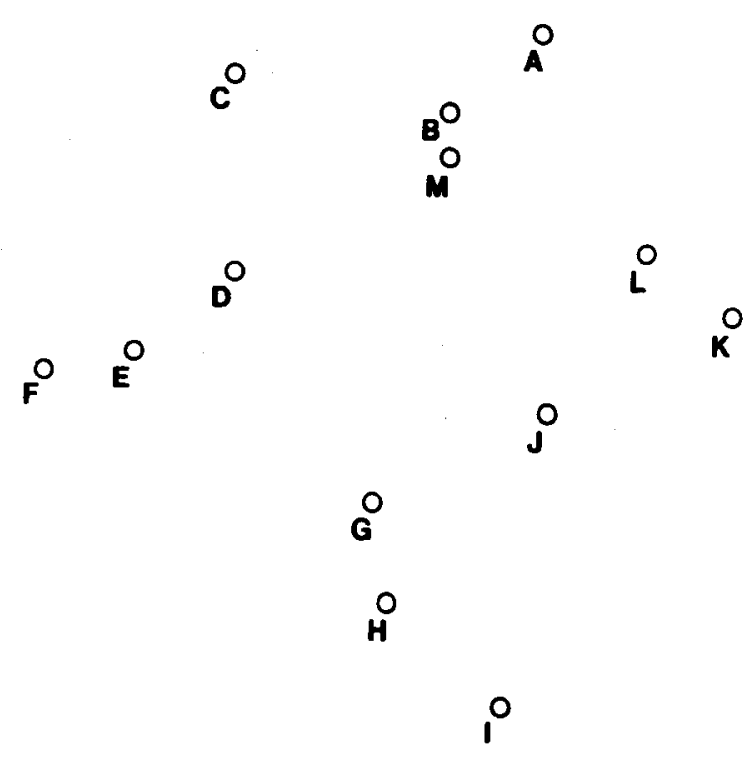

Figure 1. Map of stimulus area.

F, the nearest stake was $3 \mathrm{~m}(9.7 \mathrm{ft})$ away; at stake I, the nearest

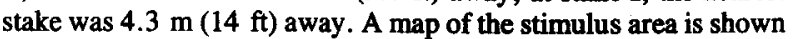
in Figure 1. Two white metal chairs were placed on either side of stake $\mathrm{F}$ and stake $\mathrm{I}$, facing the midpoint of the stimulus array. Observations were conducted on bright sunny days.

\section{Procedure}

Four observers made judgments simultaneously. Two observers were seated at stake $F$ and two were seatod at stake I. They were required to remain seated at all times, but were allowed to move their heads freely. The observers were led from the far side of the array around the perimeter of the stimulus area to their viewing positions. During the one rest period, the observers were led away from the stimulus array and directly beck to the viewing position without circling the stimulus array.

Each observer was given a package of reaponse sheets and was instructed not to share judgments with other obeervers. Three tasks were done by each observer in a fixed onder. In the first task (relative judgment), the observer indicated which two of three stakes were farthest apart; all 286 poscible sots of 3 stakes drawn from the total of 13 were judged in a rudom oxicr that was the same for each observer. In the second tack (bbolute judgment), the observer judged in feet the distance betireen all 72 possible pairs of the 13 stakes, in a random order that wes the same for all observers; accuracy of absolute judgments wes stresied. In the third task (map drawing), each observer drew a mi of the acene on a $20-\mathrm{cm}$ (8-in.) square sheet of paper; the locwion of one curtrl stake was preprinted on the map response form to serve an anchor.

Each observer made all throe of observers in the control group completed both pets from the same viewing position, two seated at location $F$ and two seated at location I. Observers in the experimental ghoup completed the two sets of judgments from two differemt viewing poritions, locations $F$ and $I$. Two observers in this group stanted location $F$ and moved to $I$, and two started at I and moved thiF. The two sets of three judgments took about $2 \mathrm{~h}$ each. There a 45 -inin rest period between sets.

\section{RESULTS}

\section{Data Analysis}

Calculation of percelved spatial layout. Data from each of the six sets of judgments for each subject were 
entered into nonmetric multidimensional scaling analyses (Young \& Lewyckyj, 1980), following a procedure used by Kosslyn et al. (1974) to examine the structure of spatial representation in memory. Responses from each measure were organized into separate dissimilarity matrices for each observer, with the number in any given cell of the matrix representing the judged distance of one stake from another.

For relative distance judgments, cell entries were the number of times an interobject distance was endorsed as being the largest in a comparison of three stakes: the numbers represent a rank-ordering of the 78 distances. Absolute distance judgments were entered directly into the dissimilarity matrices. For the maps, interobject distances were measured directly on each map to the nearest millimeter and entered into matrices. Measurement of maps was done by two independent scorers; in the case of a discrepancy between the scorers, the interobject distance in dispute was measured a third time. Each of the 8 observers provided 2 matrices for each of the three measures, for a total of 48 matrices. These were used as the input data for the multidimensional scaling. Data were treated as ordinal level scales, and a Euclidean distance solution was approximated. One-dimensional, twodimensional, and three-dimensional solutions were calculated for each matrix.

The matrix of actual interobject distances was entered into the MDS routine to produce a set of coordinates that were similar in scale to the coordinates calculated for observer judgments. This set of coordinates, which refers to the actual stimulus positions in scaled form, will be called the scaled actual layout. Procrustean rotation was used to fit the scaled judgment spaces to the scaled actual layout. Scaled coordinates were used in all layout comparisons.

Accuracy and stability of subjective spatial layout. An adaptation of a metric proposed by Kruskal (1964) is used both to compare a subjective spatial layout to the layout of the actual scene and to compare a subjective layout produced at one time to a second layout produced at a second time. This measure serves as an index of observer accuracy in the first case and consistency in the latter. It is the average absolute discrepancy between the scaled actual position of the stimulus points and the scaled observer estimates of each point:

$$
D=\Sigma \sqrt{\left[\left(X_{i}^{\prime}-X_{i}\right)^{2}+\left(Y_{i}^{\prime}-Y_{i}\right)^{2}\right]} / \mathrm{k} .
$$

where $\mathrm{k}$ is the number of stimulus points, $\left(X_{i}, Y_{i}\right)$ represents the actual coordinates of the $i$ th point, and $\left(X_{i}^{\prime}\right.$, $Y_{i}^{\prime}$ ) represents the coordinates of the estimate of the location of the $i$ th point. The average across all 13 stimulus points is used in this measure because the deviation of any one point is influenced by the total configuration.

When observer estimates are perfect, there is no discrepancy and $D=0$. The upper limit of $D$ is more difficult to specify. $D$ is calculated using MDS-scaled coordinates. The MDS program sets the scale of interobject distances to reflect standard deviation units for the particular set of judgments being scaled and centers the array on the mean of the distribution. Procrustean rotation against the scaled actual layout centers the mean of the subjective layout on the actual layout and adjusts the coordinate units to a similar standard deviation. These operations limit the scale over which $D$ is calculated, and limit the values that $D$ may obtain.

To determine some estimate of the range of $D$ under these conditions, four Monte Carlo estimation procedures were done. A number was generated randomly from the standard normal distribution and was added to the coordinates of one point of the scaled actual layout in the first study. Each stimulus point was altered in this fashion 13 times for a total of 169 variations on the actual layout. The second study altered the position of each of the 13 points of the array simultaneously by adding a random normal variate to each coordinate. One hundred altered arrays were calculated. The third study added a second random element to each coordinate of the already transformed cases produced for the second study. The fourth procedure used 100 sets of 13 points generated from a random uniform distribution with no reference to the original stimulus array at all. For each procedure, the resulting layouts were standardized along $X$ and $Y$ axes with respect to the origin and standard deviation of the stimulus array to approximate the translation and dilation effects of the Procrustean rotation used with observer judgments. No attempt was made to rotate or dilate the arrays to a best fit. $D$ values were calculated for each generated array using the original scaled actual layout as a template.

The results of these four statistical investigations are presented in Table 1. Alteration of a single point of the array resulted in an average $D$ value of 0.178 with a minimum value of 0.015 and a maximum value of 0.452 . More extensive alteration yielded average $D$ values of 0.846 and 0.969 in the first- and second-order transformations involving all stimulus points, with maximum values of 1.226 and 1.390 , respectively. The randomly generated distributions produced $D$ values between 0.798 and 1.759 . The standard deviation of the $D$ statistic with $N=100$ remained relatively stable across procedures.

The average absolute discrepancy measure, $D$, is preferred to the correlation coefficient reported by Kosslyn et al. (1974) for several reasons. The meaning of a

Table 1

Results of Four Statistical Investigations of the Characteristics of the Comparison Measure $D$

\begin{tabular}{|c|c|c|c|c|}
\hline \multirow[b]{2}{*}{$\begin{array}{c}\text { Sample } \\
\text { Characteristics }\end{array}$} & \multicolumn{4}{|c|}{ Procedure } \\
\hline & $\begin{array}{c}\text { One Point } \\
\text { Altered } \\
N=169\end{array}$ & $\begin{array}{l}\text { All Points } \\
\text { Altered } \\
\text { (Once) } \\
N=100 \\
\end{array}$ & $\begin{array}{l}\text { All Points } \\
\text { Altered } \\
\text { (Twice) } \\
N=100\end{array}$ & $\begin{array}{c}\text { Random } \\
\text { Uniform } \\
\text { Distribution } \\
\quad N=100 \\
\end{array}$ \\
\hline Minimum & 0.015 & 0.547 & 0.694 & 0.798 \\
\hline Maximum & 0.452 & 1.226 & 1.390 & 1.759 \\
\hline Mean & 0.178 & 0.846 & 0.969 & 1.291 \\
\hline Standard Deviation & 0.095 & 0.128 & 0.145 & 0.150 \\
\hline Skewness & 0.739 & 0.230 & 0.471 & -0.235 \\
\hline Kurtosis & 0.331 & 0.168 & -0.008 & 1.032 \\
\hline
\end{tabular}


multiple correlation coefficient in a situation in which the similarity between data sets has been maximized is unclear. Robustness of the correlation coefficient with a small stimulus space is suspect. Furthermore, statistical tests on the correlation coefficient rely on an assumption of heteroscedasticity, which may not be met in this experimental paradigm. The discrepancy measure has none of these objections.

The effects of position change on perception are assessed by using the coordinates $\left(X_{i}^{\prime}, Y_{i}^{\prime}\right)$ and $\left(X_{i}^{\prime}, Y_{i}^{\prime \prime}\right)$ in Equation 1, where each set of coordinates represents the observer's subjective judgments at different times. Perfect consistency across time would yield $D^{\prime}=0$. The statistical characteristics of $D^{\prime}$ would be similar to those described for $D$, since the calculation procedure is identical. Multivariate analysis on this measure of consistency was done to assess the effect of observer position on perception of the scene.

Comparison of horizontal and radial distance perception. Thirty-five of the 78 distances between stakes were chosen as a subset of interobject distances for use in the analysis of the differences in perception of depth and breadth (see Figure 2). Depth in the classical sense is referred to as radial extent, and was defined as a distance/direction that fell within $30^{\circ}$ of line of sight. Breadth, or horizontal extent, was defined as a distance/direction that fell within $30^{\circ}$ of the perpendicular as measured from the observer's position and the midpoint of the distance in the array. The 35 distances chosen were selected because they extended horizontally from one viewing position and radially from the other. Distance $\overline{\mathrm{AJ}}$, for example, is a horizontal distance when viewed from point $F$ and a radial distance when seen from location $I$. Nineteen of the chosen distances extended horizontally

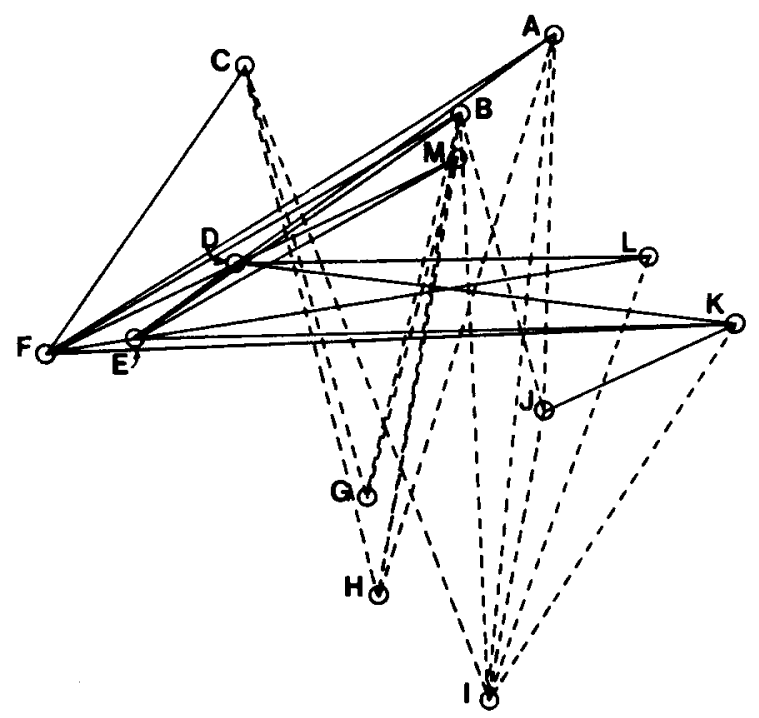

Radial to F

Radial to I - $1 .--$

Figure 2. Subsets of distances classified as horizontal when viewed from one position and radial when viewed from the second position. with respect to location I, and 16 were radial with respect to location I and horizontal from location F. The radial distance subset includes both egocentric and exocentric radial distances. Although Gogel (1977) points out that egocentricity may affect distance judgments, the present study did not investigate this factor because of its limited stimulus domain.

Subjective response to the horizontal and radial distance orientations was examined in an analysis of covariance. The difference between each observer's actual distance estimate, rank ordering, or map drawing in the first and second judgment set for each distance was the dependent measure. The observers who did not move between judgments (no-shift condition) saw each of the 35 distances in the same orientation both times: their score is the simple difference between judgments. Observers who did move (position-shift condition) saw each distance in both horizontal and radial orientations: their score for each distance is the judgment of the distance when radial minus judgment of the distance when horizontal. The magnitude of the actual distance was included as a covariate to control for the effect of stimulus magnitude on judgment error.

\section{Calculation of Perceived Spatial Layouts}

Goodness-of-fit measures were used to determine the number of dimensions needed for an adequate representation of perceived space through multidimensional scaling. MDS yields a measure of the proportion of variance of the subjective estimates explained. Since map data were gathered from two-dimensional response formats, and were scaled primarily to obtain convenient coordinate spaces, the two-dimensional solutions achieved $R^{2}=1.0$. The $R^{2}$ values for the two-dimensional solutions using the other two measures ranged between 0.87 and 0.99 . Kruskal (1964) classifies values in this range as "excellent" fits. These solutions show remarkable internal consistency.

MDS also yields a comparison of the solution space with the input data set. To detect any nonlinearities imposed on the data by the scaling, and to detect any points that were difficult for the program to fit, a plot of one against the other was considered. Systematic nonlinearities are seen as a regular pattern of a deviation from a straight line in this diagram, whereas points difficult to fit are seen as outliers. Examination of these plots revealed no such systematic deviations or discrepant points. The functions were observed to pass through the origin.

The 48 two-dimensional solution spaces were rotated and scaled to best fit with a coordinate map of the stimulus space using Procrustean factor rotation (Stenson, 1984). This step allowed direct visual comparison of obtained coordinate spaces. The coordinate spaces obtained are analogous to best-fit curves for unidimensional data.

\section{Goodness of Fit of Subjective Judgments to Actual Spatial Layout}

The accuracy statistic, $D$, was calculated as described in Equation 1 for each of the 48 solution spaces. Low 
Table 2

Difference Between Scaled Subjective and Scaled Actual Layouts for Each Observer in Each Viewing Condition Across Each Measure

\begin{tabular}{|c|c|c|c|c|c|c|}
\hline \multirow{2}{*}{$\begin{array}{l}\text { Viewing } \\
\text { Position* }\end{array}$} & \multicolumn{2}{|c|}{$\begin{array}{l}\text { Absolute Distance } \\
\text { Judgment }\end{array}$} & \multicolumn{2}{|c|}{$\begin{array}{c}\text { Relative Distance } \\
\text { Judgment } \\
\end{array}$} & \multicolumn{2}{|c|}{ Map Drawing } \\
\hline & Time 1 & Time 2 & Time 1 & Time 2 & Time 1 & Time 2 \\
\hline$F / I$ & $\begin{array}{l}.30 \\
.21\end{array}$ & $\begin{array}{l}.22 \\
.14\end{array}$ & $\begin{array}{l}.22 \\
.25\end{array}$ & $\begin{array}{l}.22 \\
.22\end{array}$ & $\begin{array}{l}.41 \\
.16\end{array}$ & $\begin{array}{l}.34 \\
.26\end{array}$ \\
\hline $\mathrm{I} / \mathrm{F}$ & $\begin{array}{l}.34 \\
.29\end{array}$ & $\begin{array}{l}.28 \\
.23\end{array}$ & $\begin{array}{l}.17 \\
.39\end{array}$ & $\begin{array}{l}.18 \\
.28\end{array}$ & $\begin{array}{l}.28 \\
.46\end{array}$ & $\begin{array}{l}.24 \\
.46\end{array}$ \\
\hline $\mathrm{F} / \mathrm{F}$ & $\begin{array}{l}.34 \\
.27\end{array}$ & $\begin{array}{l}.21 \\
.27\end{array}$ & $\begin{array}{l}.22 \\
.20\end{array}$ & $\begin{array}{l}.23 \\
.25\end{array}$ & $\begin{array}{l}.31 \\
.21\end{array}$ & $\begin{array}{l}.34 \\
.28\end{array}$ \\
\hline $\mathrm{I} / \mathrm{I}$ & $\begin{array}{l}.22 \\
.21\end{array}$ & $\begin{array}{l}.22 \\
.15\end{array}$ & $\begin{array}{l}.20 \\
.20\end{array}$ & $\begin{array}{l}.17 \\
.20\end{array}$ & $\begin{array}{l}.36 \\
.32\end{array}$ & $\begin{array}{l}.43 \\
.22\end{array}$ \\
\hline
\end{tabular}

Note-Each number represents the average absolute deviation of the subjective from the actual layout as described in Equation 1 in the text. *Position during first replication/position during second replication.

values represent greater accuracy than high values. The values of $D$ obtained from all 8 observers across both replications ranged from 0.138 to 0.339 for absolute distance judgments, from 0.170 to 0.387 for relative distance judgments, and from 0.159 to 0.460 for map drawings (Table 2).

Figure 3 shows a coordinate space with $D=0.170$ overlaid on the scaled actual layout. Figure 4 shows a poorly fit space $(D=0.343)$. These figures provide a visual representation of the meaning of $D$. The visual fit of the judgment spaces to the scaled actual layout is quite good, and the range of $D$ values is well within that described in the Monte Carlo study, which involved minimal manipulation of the stimulus space, suggesting that this range of $D$ values represents a reasonable degree of observer accuracy.

Repeated measures analysis of variance of the $D$ values evaluated the effects of group membership, initial viewing position, replication, and measurement instrument on global accuracy. The only significant effect was that the three report measures differed in overall accuracy $[F(2,8)$ $=4.62, p<.05]$. Mean $D$ values for the absolute distance, relative distance, and map measures were, respectively, $0.24,0.22$, and 0.32 . Subsequent $t$ tests to examine simple effects showed that responding was less accurate on the map measure than on either the relative distance judgment measure $[t(6)=3.53, p<.01]$ or the absolute judgment measure $[t(6)=2.4, p<.05]$. The absolute and relative distance measures did not differ significantly from each other. Observers showed no differences in accuracy across replications $[F(1,4)=2.21, p>.05]$. All other factors and interactions in the model were also nonsignificant, with $F<1.0$.

Samples of scaled layouts from each measure are shown in Figure 5. These layouts, calculated from simple judgments about each distance in the scene observed, show a good general correspondence to the actual stimulus array. The fact that the entire array can be reconstructed in this fashion from these judgments is evidence that in this setting sufficient information about spatial layout is available to the individual for accurate judgments to be made about spatial position.

Although it is tempting to speculate about the displacements of individual points in each scaled layout, as Kosslyn et al. (1974) did, the procedure involved in obtaining judgments and scaling them precludes accurate determination of the causes of displacement. This is best understood through a detailed example with reference to Figure 4. The position of point $B$ is determined most directly by estimates of the 12 distances $\overline{\mathrm{BA}}, \overline{\mathrm{BC}}, \overline{\mathrm{BD}}$,

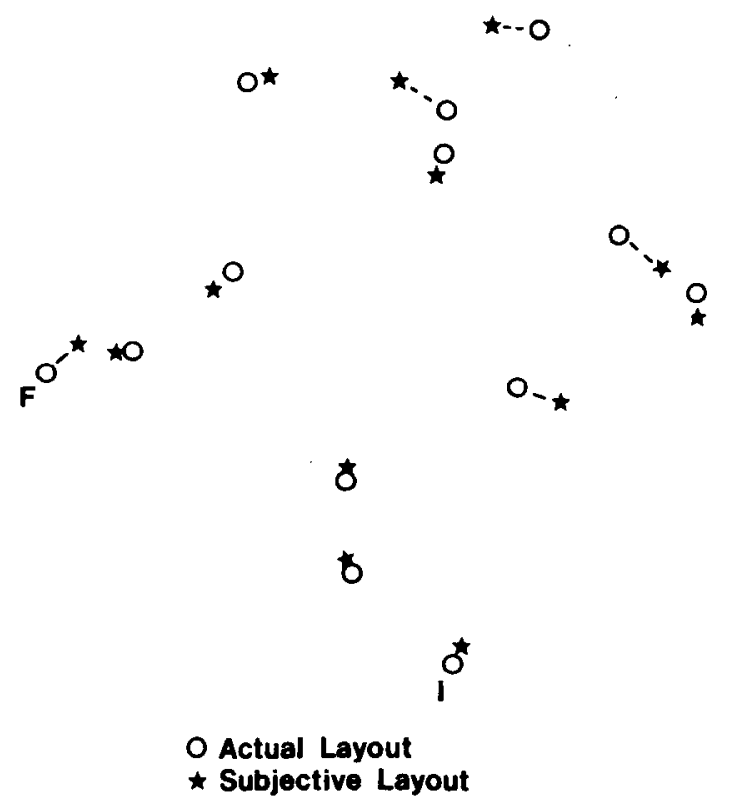

Figure 3. Comparison of actual layout to subjective data with $D=0.170$ (viewing position F).

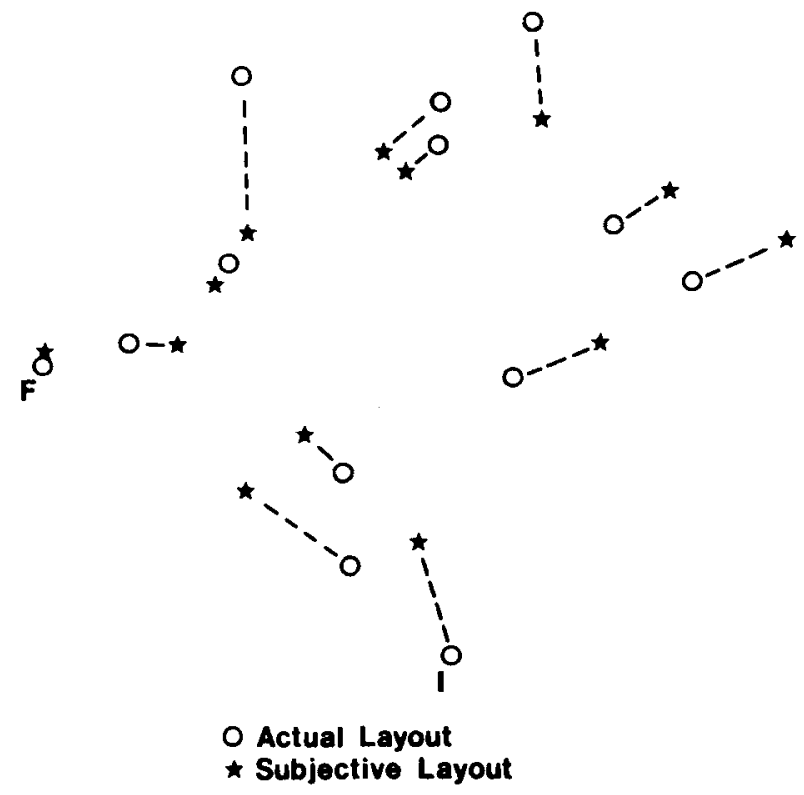

Figure 4. Comparison of actual layout to subjective data with $D=0.343$ (viewing position I). 


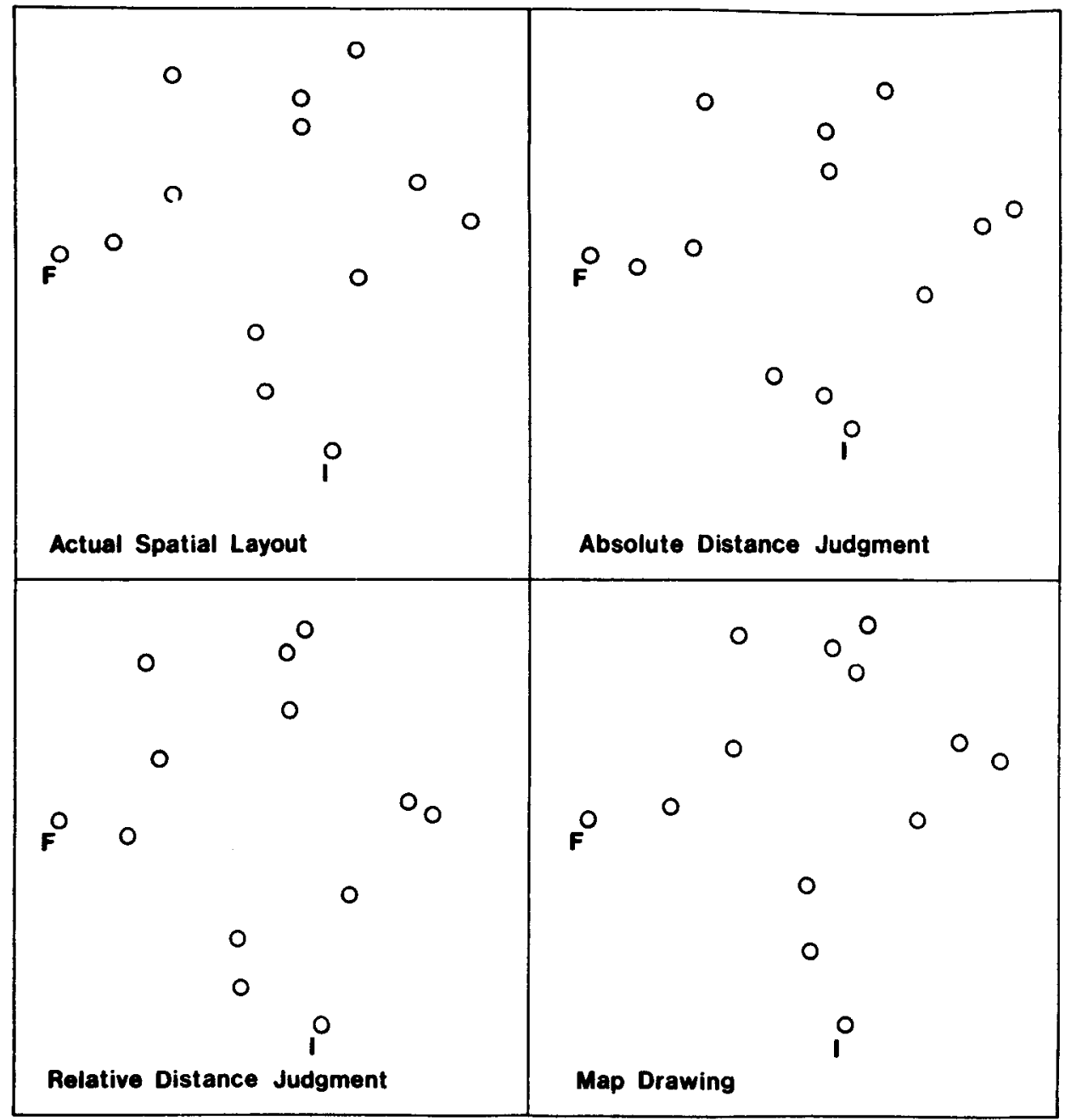

Figure 5. Examples of scaled representations of actual spatial layout and best-fit multidimensional spaces for each measure.

$\overline{\mathrm{BE}}, \overline{\mathrm{BF}}, \overline{\mathrm{BG}}, \overline{\mathrm{BH}}, \overline{\mathrm{BI}}, \overline{\mathrm{BJ}}, \overline{\mathrm{BK}}, \overline{\mathrm{BL}}$, and $\overline{\mathrm{BM}}$. Each of the other endpoints of these distances (points $A, C$ through $M$ ) is determined in turn by another subset of 12 distances. In sum, the position of point $B$ depends on all 78 estimates of distance. Although the apparent foreshortening of the position of point $B$ viewed from point $F$ might be interpreted as foreshortening of radial distances $\overline{\mathrm{BD}}, \overline{\mathrm{BE}}$, and $\overline{\mathrm{BF}}$, it might also be due to overestimation of distances $\overline{\mathrm{DF}}, \overline{\mathrm{LF}}$, and $\overline{\mathrm{JF}}$. Other possible explanations exist. The methodology used to collect the data, which allowed all points in the array to vary, precludes discussion of the direction of displacement of individual points in the scaled layouts.

\section{Effects of Observer Position}

The presence of systematic subjective distortion of the scene was investigated through a comparison of relative consistency across the two sets of judgments for the two groups of observers. If such distortion exists, observers who moved between judgment sets would be expected to show less consistency between judgments than observers who did not move, since the direction of distortion relative to the absolute coordinates of the scene would change as observer position changed. Obtained $D^{\prime}$ values are listed in Table 3.

The mean $D^{\prime}$ values in Table 4 serve to describe the effects of observer position relative to the scene on perception of the layout of that scene. Data from observers who did not move are in the first row. Those who made judgments at two different positions are shown in the bottom row. As in the calculation of $D$, low scores indicate greater agreement than high scores. The agreement across replication for the two groups was analyzed in a multivariate analysis of variance with data from all three measures entered into the model.

Wilk's lambda for the difference in viewing positions was significant at the .05 level $[F(3,4)=8.23]$. Subsequent ANOVAs proved this effect to be significant for the absolute judgment data $\left[M_{n s}=0.23, M_{x}=0.36\right.$; $F(1,5)=10.46, p<.05]$ and for the map-drawing data 
$\left[M_{n s}=0.23, M_{s}=0.47 ; F(1,5)=6.81, p<.05\right]$. The difference between viewing positions in the relative distance judgment data was not significant $\left[M_{n s}=0.18, M_{s}\right.$ $=0.26 ; F(1,5)=4.26, p>.05$ ]. All three effects were in the expected direction, however, with observers who changed position showing a worse fit between the two replications than observers who stayed in the same viewing position across replications.

\section{Comparison of Horizontal and \\ Radial Distance Perception}

One of the consequences of changing viewing position is that horizontal distances (perpendicular to the line of sight) become radial (parallel to the line of sight). The effect of this change was explored by examining the difference in judgments of the lengths of particular distances in the stimulus scene that were horizontal from one vantage point and radial from the other (Figure 2).

Analyses of covariance of the difference between two judgments of the same stimulus distance were done on all three dependent measures. The observing condition (no shift or position shift) was the variable of interest, since the effect of interest occurs only in the position-shift group. The absolute orientation of the stimulus distance (radial from $\mathrm{F}$ or radial from I) was entered into the model to control in some part for field effects. Absolute magnitude of the stimulus distance was included as a covariate. Simple differences between the judgments were used instead of ratios to preserve the linearity of the dependent measure.

Analysis of each of the three dependent measures revealed a strong main effect of the position shift/no-shift factor for all three dependent measures. The obtained $F(1,275)$ values $(26.19,35.31$, and 26.19 for map, abso-

Table 3

Average Absolute Difference Between Subjective Judgments at Two Different Times for Each Observer in Each Viewing Condition Across Each Measure

\begin{tabular}{cccc}
$\begin{array}{c}\text { Viewing } \\
\text { Position* }\end{array}$ & $\begin{array}{c}\text { Absolute Distance } \\
\text { Judgment }\end{array}$ & $\begin{array}{c}\text { Relative Distance } \\
\text { Judgment }\end{array}$ & $\begin{array}{c}\text { Map } \\
\text { Drawing }\end{array}$ \\
\hline F/I & .36 & .28 & .44 \\
& .28 & .18 & .32 \\
I/F & .41 & .24 & .39 \\
& .32 & .34 & .72 \\
F/F & .22 & .18 & .21 \\
& .27 & .21 & .29 \\
I/I & .18 & .17 & .23 \\
& .26 & .28 & .17 \\
\hline
\end{tabular}

Note-Calculation of the measure reported is described in the text. *Position during first replication/position during second replication.

Table 4

Disagreement Between Replications as a Function of Viewing Condition for Each of Three Measures

\begin{tabular}{lccc}
\hline \multicolumn{1}{c}{ Condition } & $\begin{array}{c}\text { Absolute Distance } \\
\text { Judgments }\end{array}$ & $\begin{array}{c}\text { Relative Distance } \\
\text { Judgments }\end{array}$ & $\begin{array}{c}\text { Map } \\
\text { Drawings }\end{array}$ \\
\hline No Position Shift & 0.23 & 0.18 & 0.23 \\
Position Shift & 0.36 & 0.26 & 0.47 \\
\hline
\end{tabular}

Note--Higher numbers indicate greater disagreement $(N=8)$.
Table 5

Difference Between Subjective Distance Estimates Across Replication for 35 Interobject Distances

\begin{tabular}{cccc}
\hline \multicolumn{4}{c}{ Across Replication for 35 Interobject Distances } \\
\hline Condition & $\begin{array}{c}\text { Absolute Distance Relative Distance } \\
\text { Judgments }\end{array}$ & $\begin{array}{c}\text { Map } \\
\text { Judgments* }\end{array}$ & Drawings \\
\hline No Position Shift & $\begin{array}{c}-34.14 \mathrm{~cm} \\
(-1.12 \mathrm{ft})\end{array}$ & -0.08 & $1.94 \mathrm{~mm}$ \\
Position Shift & $-245.36 \mathrm{~cm}$ & -0.91 & $-12.94 \mathrm{~mm}$ \\
& $(-8.05 \mathrm{ft})$ & & \\
\hline
\end{tabular}

Note-Each number represents a difference between judgments when the distance is horizontal and when it is radial for the position-shift group. Each number represents a difference between judgments made in replications 1 and 2 for the no-position-shift group. * *Rank order difference.

lute, and relative judgment measures, respectively) were significant beyond the .0001 level. Condition means are presented in Table 5. Observers who changed position between observations consistently estimated the stimulus distances to be shorter when seen radially than when seen horizontally. The average ratio of the radial:horizontal absolute distance estimate was 0.85 .

\section{DISCUSSION}

Observers are able to describe a scene with visibly good accuracy when in a rich stimulus situation. The subjective description of spatial layout, however, varies consistently with observer position within the scene. Preliminary findings of subsequent studies suggest that these results may be obtained even when observers have had prior experience walking through the visual array (R. N. Haber, personal communication, 1986). At least part of this variation is due to differences in the way observers perceive horizontal and radial distances. A similar finding with respect to distance orientation is reported by Wagner (1985), who used a comparable stimulus setting. Wagner found that distance compression increased as the angle of the observed distance increased from the horizontal to the radial, to a maximum compression of about $50 \%$. Gogel (1977) has differentiated egocentric from exocentric radial distances, noting greater compression in the egocentric distances. These results, in their varying degree of specificity, emphasize the importance of the subjective point of view in understanding visual space perception. This is an issue that is particularly germane to attempts to relate visual experience to other constructs such as visual memory (Kosslyn, Ball, \& Reiser, 1978) and to attempts to construct machines capable of simulating human vision.

The distinction between horizontal and radial distance perception is a common one in classical psychophysical research, but seems inconsistent with ecological psychophysics. These data, then, support the classical model of space perception. As Wagner (1985) comments, however, the visual world approaches "veridical perception as the quantity and quality of perceptual information increases" (p. 493). The methods of classical psychophysics often involve drastic reduction of the percep- 
tual information available to the observer, leading perhaps to variability or nongeneralizability of laboratory tests to natural situations. The methods outlined in this paper provide an alternative to classical laboratory study of visual space perception which maximizes the observer's access to visual information while providing the experimenter with formidable statistical control of complex stimulus events.

\section{REFERENCES}

EPSTEIN, W., \& PARK, J. (1964). Examination of Gibson's psychophysical hypothesis. Psychological Bulletin, 62, 180-196.

FARBER, J. M., \& McConKIE, A. B. (1979). Optical motion as information for unsigned depth. Journal of Experimental Psychology: Human Perception \& Performance, 5, 494-500.

FERRIS, S. H. (1972). Motion parallax and absolute distance. Journal of Experimental Psychology, 95, 258-263.

Gibson, E. J., Gibson, J. J., Smith, O. W., \& Flock, H. (1959). Motion parallax as a determinant of perceived depth. Journal of Experimental Psychology, 58, 40-51.

GiBson, J. J. (1979). The ecological approach to visual perception. Boston: Houghton Mifflin.

GiBson, J. J., \& CAREL, W. (1952). Does motion perspective independently produce the impression of a receding surface? Journal of Experimental Psychology, 44, 16-18.

GILINSKY, A. S. (1951). Perceived size and distance in visual space. Psychological Review, 58, 460-482.

GoGEL, W. C. (1977). The metric of visual space. In W. Epstein (Ed.), Stability and constancy in visual perception (pp. 129-182). New York: Wiley.

Gogel, W. C., \& Tietz, J. D. (1979). A comparison of oculomotor and motion parallax cues of egocentric distance. Vision Research, 19, 1161-1170.

Goodson, F. E., Snider, T. Q., \& Swearingen, J. E. (1980). Motion parallax in the perception of movement by a moving subject. Bulletin of the Psychonomic Society, 6, 87-88.

Graham, C. H., Baker, K. G., Hecht, M., \& Lloyd, V. V. (1948). Factors influencing thresholds for monocular movement parallax. Perception \& Psychophysics, 22, 526-530.

GuLCK, W. L., \& Lawson, R. B. (1976). Human stereopsis. New York: Oxford University Press.

HABER, R. N. (1980). Perceiving space from pictures: A theoretical analysis. In M. A. Hagen (Ed.), The perception of pictures (Vol. 1, pp. 3-31). New York: Academic Press.
HABER, R. N. (1984, August). Toward a theory of the perceived layout of scenes. Paper presented at the Conference on Human and Machine Vision II, Montreal, Canada.

Hagen, M. A., Teghtsoonian, M. (1981). The effects of binocular and motion-generated information on the perception of depth and height, Perception \& Psychophysics, 30, 257-265.

Held, R. Leibowitz, H. W., \& Teuber, H. L. (Eds.) (1978). Handbook of sensory physiology: Vol. VIII, Perception. Heidelberg: Springer.

Hell, W., \& Freeman, R. B. (1977). Detectability of motion as a factor in depth perception by monocular movement parallax. Perception \& Psychophysics, 22, 526-530.

Hochberg, J. E. (1978). Perception (2nd ed.) Englewood Cliffs, NJ: Prentice-Hall.

IRWIN, D. E., YanTIS, S., \& JonIDES, J. (1983). Evidence against visual integration across saccadic eye movements. Perception \& Psychophysics, 39, 49-57.

Kosslyn, S. M., BALL, J. M., \& ReISER, B. J. (1978). Visual images preserve metric spatial information: Evidence from studies of image scanning. Journal of Experimental Psychology: Human Perception \& Performance, 4, 47-60.

Kosslyn, S. M., Pick, H. L., Fariello, G. R. (1974). Cognitive maps in children and men. Child Development, 45, 707-716.

KRUSKAL, J. B. (1964). Multidimensional scaling by optimizing goodness of fit to a nonmetric hypothesis. Psychometrika, 29, 1-27.

MARKs, L. E. (1974). Sensory processes: The new psychophysics. New York: Academic Press.

Michaels, C. F., \& Carello, C. (1981). Direct perception. Englewood Cliffs, NJ: Prentice-Hall.

RUNESON, S. (1977). On the possibility of "smart" perceptual mechanisms. Scandinavian Journal of Psychology, 18, 172-179.

STENSON, H. (1984). FORTRAN program to compute Procrustean rotation [Computer program]. Chicago: H. S. Stenson, Department of Psychology, University of Illinois at Chicago.

Wagner, M. (1985). The metric of visual space. Perception \& Psychophysics, 38, 483-495.

WHEELER, D. G., \& RoCK, I. (1982, November). What is the role of motion parallax in perception? Paper presented at the meeting of the Psychonomic Society, San Diego.

YouNG, F. W., \& LEWYCKYJ, R. (1980). The ALSCAL procedure. SAS user's guide technical supplement. Cary, NC: SAS Institute, Inc.

(Manuscript received September 23, 1985; revision accepted for publication June 20, 1986.) 